\title{
Liraglutide alters DPP4 in the circumvallate papillae of type 2 diabetic rats
}

\author{
Xun Cao', Xiao Zhou'², Xiao-Min Liu' ${ }^{1}$ and Li-Hong Zhou' \\ 1Department of Endocrinology, Harbin Medical University, Harbin, Heilongjiang Province, China \\ 2Department of Human Anatomy and Embryology, Harbin Medical University, Harbin, Heilongjiang \\ Province, China
}

Correspondence should be addressed to Xiao-Min Liu or Li-Hong Zhou

Email

liuxiaomin57@aliyun.com or zlh1972@126.com

\begin{abstract}
Liraglutide, a human glucagon-like peptide (GLP1) analog that partially inhibits dipeptidyl-peptidase 4 (DPP4), can decrease glucose levels and suppress appetite in patients with type 2 diabetes (T2DM). GLP1 and its receptor (GLP1R) also exist in the taste buds of rodents and regulate taste sensitivity. DPP4, a protease, functions in homeostasis of blood glucose, lipids, and body weight. Interactions among GLP1, GLP1R, and DPP4 likely affect taste and food-intake behavior. The aim of the present study was to investigate DPP4 expression in the taste buds of the circumvallate papillae (CV) in T2DM rats, and determine the effects of liraglutide treatment. Rats were divided into diabetic control (T2DM-C), normal control (NC), and liraglutide-treated diabetic (T2DM + LIR) groups. DPP4 localization and gene expression levels were evaluated by immunohistochemistry and quantitative reverse transcription-polymerase chain reaction (RT-qPCR), respectively. DPP4 immunoreactive cells were localized in the taste buds of the rat CV. RT-qPCR showed significantly higher expression of Dpp4 mRNA in both the taste buds and hypothalamus of T2DM-C rats compared with NC rats. However, in the T2DM + LIR group, Dpp4 expression differed between the taste buds and hypothalamus, with significantly higher and lower levels compared with the T2DM-C group, respectively. Dpp4 mRNA expression is increased in the taste buds of the CV of T2DM rats. Liraglutide simultaneously upregulated (taste buds) and downregulated (hypothalamus) Dpp4 expression in T2DM rats. Therefore, DPP4 may be closely associated with the anorexigenic signaling and weight loss induced by the treatment of liraglutide in type 2 diabetic patients.
\end{abstract}

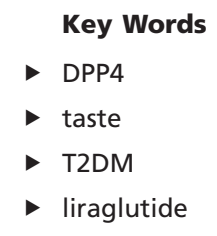

Journal of Molecular

Endocrinology

(2016) 57, 13-21

\section{Introduction}

Dipeptidyl-peptidase-4 (DPP4) is a $110 \mathrm{kDa}$ membranebinding peptidase, which was originally discovered in 1966 by Hopsu-Havu and Glenner (1966). In particular, DPP4, also known as CD26 (Kameoka et al. 1993), is a cell-surface aminopeptidase with serine protease activity, belonging to the S9B family of serine proteases (Röhrborn etal. 2015). It is expressed on the apical surfaces of epithelial and acinar cells and in endothelial cells, fibroblasts, and lymphocytes (Dinjens et al. 1989, Mentzel et al. 1996); however, DPP4 also exists as a soluble circulating form in plasma (Kikuchi et al. 1988). DPP4 shows broad expression patterns in many organs, including the liver, biliary

Published by Bioscientifica Ltd. 
tract, exocrine pancreas, islet, spleen, small intestine, and brain, in both rodents and humans (Itou et al. 2013, Liehua et al. 2014). This widespread distribution indicates that DPP4 likely exerts pleiotropic biological activities (Hildebrandt et al. 2000). By means of the degradation of glucagon-like peptide-1 (GLP1), DPP4 plays an important role in regulating glucose homeostasis and anorexigenic signaling (Raun et al. 2007). Accordingly, DPP4 inhibitors are approved for the treatment of type 2 diabetes mellitus (T2DM), and recognition of the importance of this molecule with respect to basic and clinical research has increased substantially in recent years. These inhibitors, collectively known as gliptins, increase GLP1 levels and therefore prolong postprandial insulin action. Despite the wide clinical use of DPP4 inhibitors, knowledge of the regulation mechanisms of DPP4 under conditions of altered glucose and body weight, especially in T2DM, is limited. Moreover, in most studies, DPP4 enzyme activity has been assessed, with scarce reports on DPP4 expression at the protein and mRNA levels (Hildebrandt et al. 2001, Kirino et al. 2012, Stengel et al. 2014).

Liraglutide shows $97 \%$ sequence identity to native GLP1 and contains an additional 16-carbon fatty acid that can inhibit DPP4 and serve as a long-acting GLP1 receptor (GLP1R) agonist. The duration of action of liraglutide is sufficient to enable once-daily administration by subcutaneous injection for the treatment of T2DM and obesity (Degn et al. 2004, Raun et al. 2007); however, the exact mechanisms by which liraglutide induces weight loss and appetite suppression are not fully understood. Recently, we and other groups independently found that GLP1 and GLP1R are expressed in the taste buds of both animals and humans, that GLP1 signaling acts to modulate sweet, sour, and umami taste sensitivity (Feng et al. 2008, Shin et al. 2008, Martin et al. 2009), and that there are significant differences in these parameters in diabetic and/or obese individuals (Feng et al. 2012, Zhang et al. 2013). Collectively, these findings indicate that GLP1 is an important peptide for the regulation of taste senses. However, little is known about the patterns and possible changes in DPP4 expression in the taste buds of the rat or human circumvallate papillae (CV) under normal and abnormal metabolic status, especially after liraglutide treatment. Furthermore, the relationship between DPP4 expression in the taste buds and hypothalamus under these conditions remains unexplored. Therefore, this study was designed to explore whether DPP4 is coexpressed with its substrate peptide GLP1 in the rat taste buds, and to evaluate the influence of liraglutide treatment on DPP4 expression in diabetic and/or obese rats.

\section{Materials and methods}

\section{Animals}

Forty-two male Wistar rats (purchased from Liaoning ChangSheng Biotechnology Co, Liaoning, China), weighing 180-200g, 8-10 weeks old, were individually housed under controlled room temperature $\left(22 \pm 2^{\circ} \mathrm{C}\right)$ and humidity $(55 \pm 5 \%)$, with a $12 \mathrm{~h}$ light: $12 \mathrm{~h}$ darkness cycle. Water and food were provided ad libitum. All procedures adhered to the National Institutes of Health Guide for the Care and Use of Laboratory Animals. After 1-week habituation, the rats were randomly divided into high-fat $(n=30,45 \%$ carbohydrate, $15 \%$ protein, $40 \%$ fat) and normal control (NC, $n=12,68 \%$ carbohydrate, $23 \%$ protein, $9 \%$ fat) diet groups. After 8 weeks, the rats fed a high-fat diet and received i.p. injection of $30 \mathrm{mg} / \mathrm{kg}$ streptozotocin (Sigma-Aldrich), while NC rats received a comparable injection of saline. Seventy-two hours following the treatment, 24 rats with nonfasting blood glucose levels $\geq 300 \mathrm{mg} / \mathrm{dL}(16.7 \mathrm{mM})$ were considered to be T2DM rats (Srinivasan et al. 2005) and were continued on the high-fat diet. Eight weeks later, 12 of these rats were treated once daily with liraglutide (T2DM+LIR, $0.2 \mathrm{mg} / \mathrm{kg}$, s.c.) for 4 weeks, and the remaining 12 diabetic rats served as the diabetic control (T2DM-C) group. The dose for liraglutide $(0.2 \mathrm{mg} / \mathrm{kg})$ was selected based on its efficacy in diabetes patients (i.e. 0.6-1.8 mg) (Peterson \& Pollom 2010), and designed according to the guidelines provide by the Centre for Drug Evaluation and Research (CDER) at the Food and Drug Administration (ReaganShaw et al. 2008). Both NC and T2DM-C rats were injected with saline once daily. Food intake was recorded twice a week and body weight (BW) and nonfasting blood glucose (BG) levels were determined weekly.

\section{Blood assays}

After 4 weeks of treatment with liraglutide, fasted rats were injected intraperitoneally with $10 \%$ chloral hydrate $(0.3 \mathrm{~mL} / 100 \mathrm{~g})$ after overnight food deprivation. BW was measured and blood was drawn from the right ventricle. Serum samples were centrifuged and stored at $-80^{\circ} \mathrm{C}$ until assayed. The blood samples were examined for BG analysis, which was done by a hexokinase method using the Glucose Estimation Kit (Huili Biotech, Changchun, China) (Zhang et al. 2013). Blood total triglyceride (TG) and cholesterol (TC) levels were measured using commercial assay kits (Huili Biotech, Changchun, China). Insulin was measured with an enzyme-linked immunoassay kit (EMD Millipore).

Published by Bioscientifica Ltd. 


\section{Immunohistochemistry}

Small blocks of tissue containing the $\mathrm{CV}$ of the rats were quickly dissected immediately after killing. The streptavidin-peroxidase (SP) method was used for immunohistochemical staining. Excised tissues were immersed in a solution of $4 \%$ paraformaldehyde for $24 \mathrm{~h}$ and processed for embedding in paraffin wax. Tissue sections ( $7 \mu \mathrm{m}$ thick) were cut serially, dewaxed and rehydrated, rinsed with distilled water and phosphatebuffered saline (PBS), quenched with $3 \% \mathrm{H}_{2} \mathrm{O}_{2}$, and incubated with citrate buffer $(\mathrm{pH}$ 6.0) for $20 \mathrm{~min}$ at $100^{\circ} \mathrm{C}$ for antigen retrieval (Shi et al. 2002). Then, nonspecific binding was reduced by pretreatment with $3 \%$ normal goat serum for $20 \mathrm{~min}$ and incubated with a rabbit polyclonal antibody against DPP4 (Abcam) at a dilution of $1: 400$ at $4^{\circ} \mathrm{C}$ overnight. The slides were then washed with PBS. The secondary goat anti-rabbit IgG antibody (Boster, Wuhan, China) was applied at room temperature followed by a PBS rinse. Then, SP was applied followed by a PBS rinse. The sections were developed by reaction in $0.05 \% 3,3^{\prime}$-diaminobenzidine tetrahydrochloride and $\mathrm{H}_{2} \mathrm{O}_{2}$. They were then rinsed, dehydrated through a graded series of ethanol, cleared in xylene, and cover-slipped.

The slides were observed under light microscopy (CX31; Olympus). Each slide was examined by two independent observers. Twenty immunopositive taste buds from each rat were randomly selected to count the number of DPP4-immunopositive cells. Data were analyzed quantitatively by cell counts according to the protocol described previously (Shen et al. 2005).

\section{Total RNA extraction and quantitative reverse transcription-polymerase chain reaction (RT-qPCR)}

The CV taste buds and hypothalami were collected quickly and stored at $-80^{\circ} \mathrm{C}$. Total RNA was extracted using the TRIzol reagent according to the manufacturer's protocol (Roche Applied Science). After assaying the RNA concentration using a Multiskan Spectrum spectrophotometer (Thermo Fisher Scientific), RNA was reverse transcribed to cDNA with a commercial PrimeScript RT Reagent Kit (Takara Bio). The harvested materials were amplified by PCR using gene-specific primer pairs (Table 1) and the SYBR Green PCR Master Mix (Roche Applied Science).

The RT-qPCR amplification conditions were $95^{\circ} \mathrm{C}$ (10 min), followed by 40 cycles at $95^{\circ} \mathrm{C}(15 \mathrm{~s})$ and $60^{\circ} \mathrm{C}$ (1 min). $\beta$-actin was used as an internal control to normalize the amount of input RNA. Relative mRNA expression levels were calculated by the cycle threshold $\left(2^{\Delta \Delta} \mathrm{Ct}\right)$ method.

\section{Statistical analyses}

Statistical analyses were performed using SPSS 17.0 software (SPSS). Results are expressed as mean \pm s.E.M. Data were compared among the T2DM+LIR, T2DM-C, and NC groups with one-way analysis of variance. Data handling and graph generation were processed using GraphPad Prism (v6.0) software. A value of $P<0.05$ was considered to be statistically significant.

\section{Results}

\section{Body weight and food intake}

T2DM rats obtained significant final body weight when compared with NC rats $(332.8 \pm 4.60$ vs $301.6 \pm 3.07$, $P<0.001$ ) (Table 2). Food intake was also greater in T2DM rats (Table 2).

T2DM-C and T2DM+LIR rats had similar BWs and food intake before liraglutide treatment. During the treatment period, T2DM+LIR rats showed gradually reduced BW gain (Fig. 1A) and then a significant mean BW loss (332 \pm 7 to $309 \pm 6 \mathrm{~g}$ ) at the end of 4 weeks. By contrast, the T2DM-C group exhibited the highest mean levels of BW gain (Fig. 1B). Food intake was lower in the

Table 1 Sequences of primers employed for RT-qPCR amplifications.

\begin{tabular}{|c|c|c|c|c|}
\hline Gene & GenBank accession no. & Forward primer $\left(5^{\prime}-3^{\prime}\right)$ & Reverse primer $\left(5^{\prime}-3^{\prime}\right)$ & Product length (bp) \\
\hline \multirow[t]{2}{*}{ DPP-IV } & NM_012789.1 & GCAAGACGTGG & AGCCTGGTTGGG & 101 \\
\hline & & GTAATGATG & TTTGTATG & \\
\hline \multirow[t]{2}{*}{ Proglucagon } & NM 012707.2 & TGCTGAAGGGAC & GCCTTTCACCAGC & 85 \\
\hline & & CTTTACCAGTGA & CAAGCAATGAA & \\
\hline \multirow[t]{2}{*}{ GLP-1R } & NM 012728.1 & CTGCATCGTGATA & GGACTTCGCGAG & 73 \\
\hline & & GCCAAGCT & TCTGCATT & \\
\hline \multirow[t]{2}{*}{$\beta$-actin } & NM_031144.3 & GGAGATTACTGC & GACTCATCGTACT & 150 \\
\hline & & CCTGGCTCCTA & CCTGCTTGCTG & \\
\hline $\begin{array}{l}\text { http://jme.endoc } \\
\text { DOI: 10.1530/JM }\end{array}$ & journals.org & $\begin{array}{l}\text { for Endocrinology } \\
\text { ted in Great Britain }\end{array}$ & Bioscientifica Ltd. & \\
\hline
\end{tabular}


Table 2 Mean body weight, food intake of NC, and T2DM rats.

\begin{tabular}{|c|c|c|c|c|}
\hline & Initial body weight (g) & Final body weight (g) & Body weight gain (g) & Food intake (g/day) \\
\hline $\mathrm{NC}(n=12)$ & $189.7 \pm 1.75$ & $301.6 \pm 3.07$ & $111.9 \pm 3.43$ & $20.11 \pm 0.36$ \\
\hline T2DM $(n=24)$ & $189.5 \pm 1.09 * *$ & $332.8 \pm 4.60 * *$ & $143.3 \pm 4.77 * *$ & $29.78 \pm 0.54 * *$ \\
\hline
\end{tabular}

**Compared with NC group, $P<0.001$. NC, normal control rats; T2DM, diabetic rats.

T2DM + LIR group than in the T2DM-C group, and the NC group showed the lowest food intake (Fig. 1C).

\section{Blood assays}

T2DM-C rats had the highest levels of BG, TG, TC, and FINS (Table 3). However, BG, TC, TG, and FINS were greater in T2DM+LIR group than in NC group (Table 3 ).

\section{Immunohistochemistry}

Immunoreactivity for DPP4 was observed in the taste bud cells of the rat CV (Fig. 2). The numbers of DPP4 immunoreactive taste bud cells in each bud of the CV in T2DM-C rats were significantly higher than those in the NC group $(3.90 \pm 0.15$ vs $2.11 \pm 0.15, P<0.001)$ and were lower than those in T2DM+LIR rats $(3.90 \pm 0.15$ vs $5.63 \pm 0.27, P<0.001$ ) (Fig. 2).

\section{RT-qPCR}

RT-qPCR demonstrated that Dpp4 mRNA was highly expressed in the taste buds of the rat $\mathrm{CV}$. The relative expression of Dpp4 mRNA in the taste buds in the CV $(3.05 \pm 0.07)$ was significantly higher $(P<0.001)$ than that in the hypothalamus of NC rats (Fig. 3).

In the taste buds, the mean levels of Dpp4 and proglucagon mRNA expression in both the T2DM-C and $\mathrm{T} 2 \mathrm{DM}+$ LIR groups were significantly higher than those in the NC group $(P<0.001)$, while T2DM+LIR rats showed significantly higher $(P<0.001)$ Dpp4 and proglucagon mRNA expression than the T2DM-C group (Fig. 4).
Glp1r mRNA expression was not significantly different among the three groups $(P>0.05)$ (Fig. 4).

In the hypothalamus, the mean expression levels of $D p p 4$ and proglucagon mRNA in the T2DM-C group were significantly increased than those in both the NC group and T2DM+LIR group $(P<0.001)$, whereas Dpp4 expression was decreased and proglucagon was increased in the T2DM+LIR group compared with the NC group $(P<0.001)$ (Fig. 5). Compared with $\mathrm{NC}$ and T2DM-C groups, the mRNA expression of Glp1r in T2DM+LIR group was significantly increased $(P<0.001)$, whereas $\mathrm{NC}$ and T2DM-C rats expressed similar levels of Glp1r $(P>0.05)$ (Fig. 5).

\section{Discussion}

Recently, growing evidence has indicated that liraglutide, a classical GLP1 analog, is effective in controlling glucose homeostasis, and reducing body weight and appetite (Cummings et al. 2010, Anna et al. 2014). However, administration of DPP4 inhibitors, which prolong the longevity of native GLP1, results in only negligible weight loss (Raun et al. 2007, Niswender et al. 2013). Thus, the mechanism by which long-acting GLP1R agonists regulate weight loss and induce anorectic effects remains unknown. It is reasonable to suppose that as a substrate enzyme, DPP4 should be coexpressed and interact with GLP1 in the taste buds of the rat CV. We hypothesized that both GLP1 and DPP4 may determine taste sense and energy balance, especially in the context of type 2 diabetic status with or without GLP1R agonist treatment. In the present study, we showed that: (1)
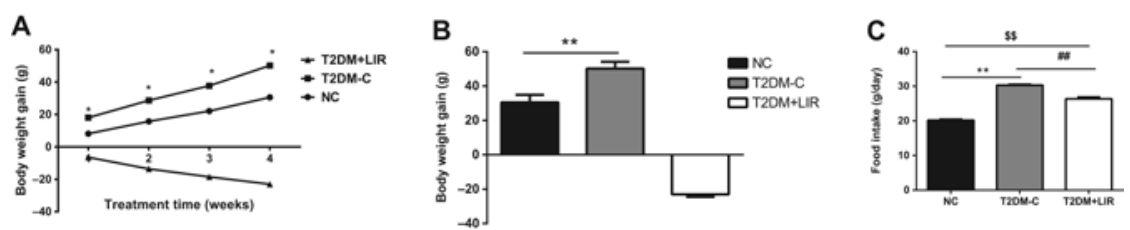

\section{Figure 1}

Body weight gain and food intake in NC, T2DM-C and T2DM + LIR rats. (A) Body weight gain of every week during treatment time. (B) Total body weight gain after treatment. (C) Mean daily food intake during treatment time. *Compared with NC group, $P<0.05$, **compared with NC group, $P<0.001$, \#"Compared with T2DM-C group, $P<0.001$, \&\&compared with NC group, $P<0.001$. NC, normal control rats; T2DM-C, diabetic control rats; T2DM + LIR, diabetic rats treated with liraglutide. 
Table 3 Changes in blood chemistry parametes in the three groups of rats.

\begin{tabular}{|c|c|c|c|c|}
\hline & BG $(\mathrm{mmol} / \mathrm{L})$ & TG $(\mathrm{mmol} / \mathrm{L})$ & TC (mmol/L) & Insulin $(\mathrm{ng} / \mathrm{mL})$ \\
\hline$N C(n=12)$ & $5.2 \pm 0.1$ & $0.82 \pm 0.01$ & $1.61 \pm 0.01$ & $1.12 \pm 0.01$ \\
\hline T2DM-C $(n=12)$ & $18.9 \pm 0.4^{*}, \#$ & $1.78 \pm 0.03 *, \#$ & $2.57 \pm 0.03 *$ & $1.67 \pm 0.02 *$ \\
\hline $\mathrm{T} 2 \mathrm{DM}+\mathrm{LIR}(n=12)$ & $8.4 \pm 0.4 \&$ & $1.29 \pm 0.03^{\&}$ & $2.32 \pm 0.04 \&$ & $1.24 \pm 0.01 \&$ \\
\hline
\end{tabular}

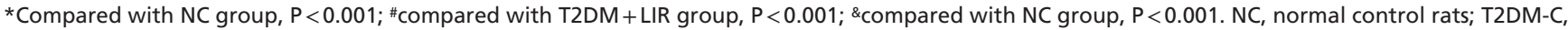
diabetic control rats; T2DM + LIR, diabetic rats treated with liraglutide. BG, blood glucose; TG, total triglycerides; TC, total cholesterol.

DPP4 is expressed in the taste bud cells of the rat CV, (2) DPP4 expression is higher in the CV and hypothalamus of T2DM-C rats, and (3) liraglutide treatment could elevate DPP4 expression in the CV but reduce it in the hypothalamus. However, previous studies evaluating the expression of DPP4 in the taste buds have revealed conflicting results. Shin and coworkers (Shin et al. 2008) showed that little or no DPP4 was expressed in the taste
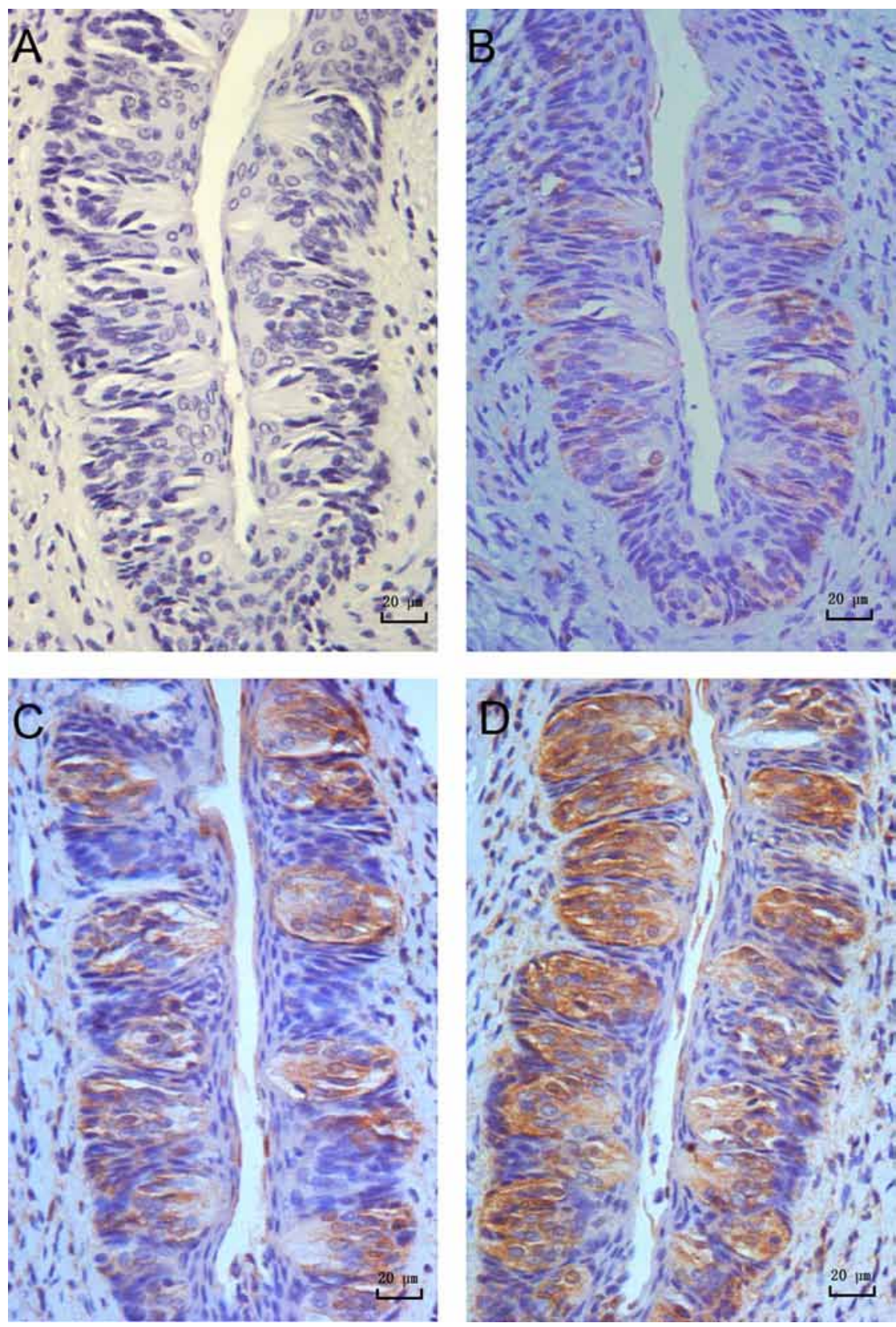

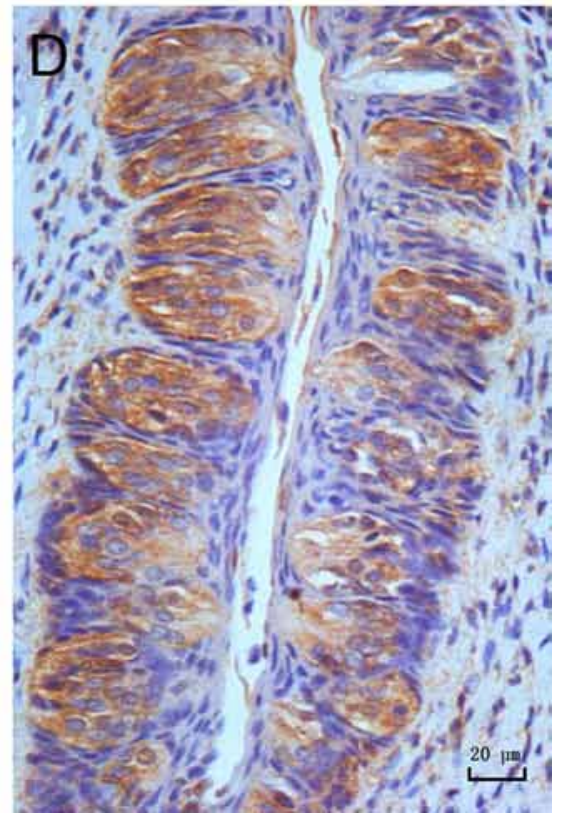

\section{Figure 2}

DPP-IV immunolocalization in circumvallate taste buds of NC, T2DM-C and T2DM + LIR rats.

(A) Negative control section where isotype control IgG instead of the primary antibody. (B) DPP-IV immunopositive cells were labeled in circumvallate papillae of NC rats. (C) DPP-IV immunopositive taste cells were more expressed in T2DM-C rats than NC rats. (D) T2DM + LIR rats showed the most DPP-IV positive cells among three groups. Scale $\mathrm{bar}=20 \mu \mathrm{m}$. A full colour version of this figure is available at http://dx.doi.org/10.1530/JME-16-0001. http://jme.endocrinology-journals.org DOI: 10.1530/JME-16-0001
๑ 2016 Society for Endocrinology Printed in Great Britain
Published by Bioscientifica Ltd 


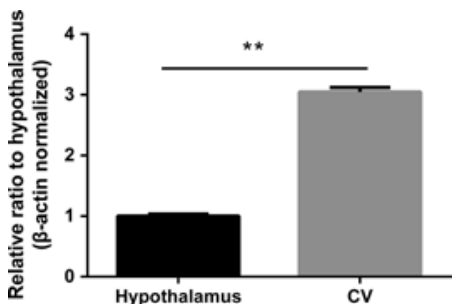

Figure 3

DPP-IV mRNA expression in the CV and hypothalamus of 7 months old male Wistar rats. DPP4 was significantly more highly expressed in the CV than in the hypothalamus. Data are expressed as mean \pm S.E.M. $* * P<0.001$ vs hypothalamus. CV, circumvallate papillae.

buds of the rat CV, whereas Dubový (1988) suggested that DPP4 is expressed in the taste buds and nerve structures of the cat fungiform papillae. The precise factors contributing to these remarkably different conclusions are still unclear; therefore, further exploration of this issue is warranted. Our experiments were carried out in triplicate and each were replicated at least twice, indicating that the conclusions are likely robust. These findings provide new insight into the functions of DPP4 within the gustatory system, and suggest that GLP1, GLP1R, and DPP4 as well as their localized interaction may all take part in the GLP1 signaling pathway to modulate taste sensitivity.

Taste impairment is one of the common complications of T2DM (Ziółkowska 2006); however, the exact pathogenesis of this symptom is unclear. In this study, we found that DPP4 expression was elevated in both the CV and hypothalamus in the T2DM-C rats. This result is in line with most previous studies (Mao et al. 2009, Lee et al. 2013), indicating that DPP4 may be closely associated with the anorexigenic signaling and weight loss induced by the treatment of GLP1R agonists in type 2 diabetic patients.

Interestingly, in this study, we observed the same trend in the expression levels of DPP4 and proglucagon (GLP1 precursor) in both CV and hypothalamus of T2DM-C rats. GLP1 are target to DPP4 resulting in cleavage and inactivation, therefore we postulate that the changes in DPP4 level in diabetic rats may be an indirect compensation of the changes of GLP1 level in the CV and hypothalamus. Moreover, as a serine protease, DPP4 cleaves numerous substrates except GLP1, including GLP2, GIP, neuropeptide Y, peptide YY, pancreatic polypeptide (PP), ghrelin, and various paracrine chemokines, which further amplifies its complexity of action (Mentlein 1999). DPP4 and GLP1 are also important regulatory peptides in energy regulation, and different metabolic states affect their expression levels. A previous study also showed that obese patients had higher DPP4 protein levels compared with normal weight and anorexics resulting in a positive correlation with BMI. While no differences across groups were observed for GLP1, a negative association was observed between PP and DPP4 protein concentration. This finding might give rise to a role for DPP4 in the enhanced degradation of PP resulting in decreased PP levels and consequently decreased food intake-inhibitory signaling under conditions of obesity, which might play a role in the pathogenesis of obesity and/or the perpetuation of the disease (Stengel et al. 2014). Therefore, the observed changes in the expression levels of DPP4 and proglucagon in the CV and hypothalamus indicate that metabolic homeostasis of whole body is a complex mechanism network, which require further investigation.

Shin and coworkers found that GLP1 and GLP1R are expressed in rat taste buds, and Glp1r-knockout mice showed dramatically reduced taste responses to sweeteners in behavioral assays, which indicated that Glp1 signaling normally acts to maintain or enhance sweet taste sensitivity (Shin et al. 2008). We observed upregulation of proglucagon in CV of T2DM-C rats. This result is in line with most previous studies. Zhang and coworkers observed that proglucagon was increased in circumvallate taste buds of high-fat-diet-induced obese rats (Zhang et al. 2013). Feng and coworkers found that the number of GLP1-positive cells in diabetic rat's von Ebner's gland was significantly higher than those in normal controls (Feng et al. 2012). Therefore, the increased GLP1 in CV may be an enhancement in sweet taste sensitivity, and the increased sweet taste preference may be secondary to changes in sweet taste sensitivity. Martin and coworkers
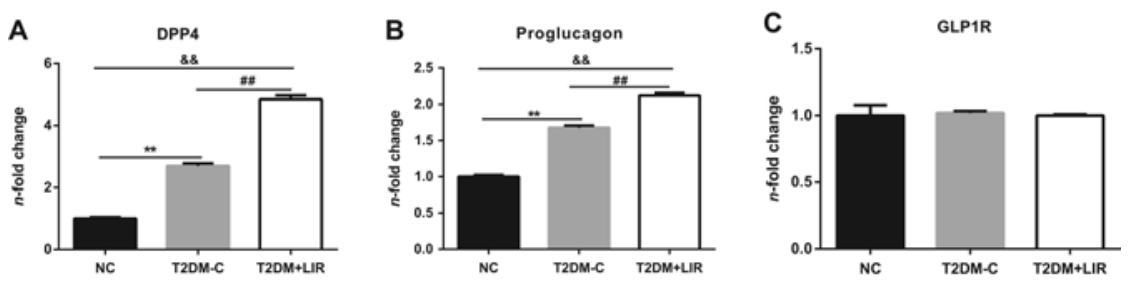
Figure 4
mRNA expressions of DPP4, Proglucagon and GLP1R in the CV of NC, T2DM-C and T2DM + LIR rats. (A) DPP4. (B) Proglucagon. (C) GLP1R. **Compared with NC group, $P<0.001$, \#\#compared with T2DM-C group, $P<0.001$, \&\&compared with NC group, $P<0.001$. NC, normal control rats; T2DM-C, diabetic control rats; T2DM + LIR, diabetic rats treated with liraglutide.


A

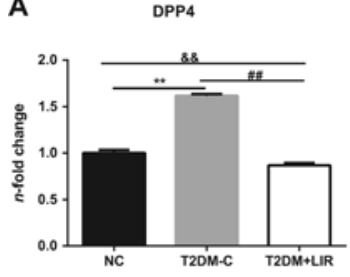

B

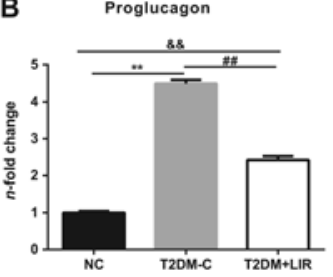

C

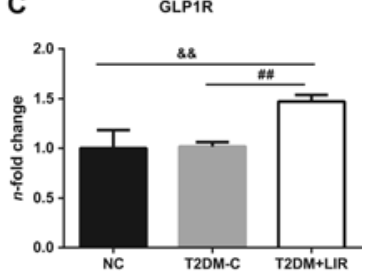

Figure 5

mRNA expressions of DPP4, Proglucagon and GLP1R in the hypothalamus of NC, T2DM-C and T2DM + LIR rats. (A) DPP4. (B) Proglucagon. (C) GLP1R. **Compared with NC group, $P<0.001$, \#\#compared with T2DM-C group, $P<0.001$, \&\&compared with NC group, $P<0.001$. NC, normal control rats; T2DM-C, diabetic control rats; T2DM + LIR, diabetic rats treated with liraglutide. demonstrated lipid-mediated release of GLP1 in mouse taste buds from the circumvallate papilla (Martin et al. 2012); therefore, we suspect that high-fat feeding may lead to upregulation of proglucagon.

In the present study, we observed a decreased BW gain, food intake, and BG level in the T2DM+LIR rats. However, the finding of increased and decreased DPP4 expression in the $\mathrm{CV}$ and hypothalamus, respectively, after liraglutide treatment may reflect different mechanisms of action. This reverse response to the same stimulation may implicate a major role of paracrine processes, and could be associated with reflex actions between peripheral sensors and the central nervous system related to food intake and anorexia. Although the mechanism is likely complex and remains unclear, the final effects of the local changes in DPP4 expression secondary to liraglutide treatment are undoubtedly beneficial not only with respect to appetite suppression but also for maintaining energy balance; indeed, there is substantial clinical evidences to support this idea. GLP1 and GLP1R are expressed in the taste buds of all mammals, indicating a paracrine rather than endocrine mechanism of action, and local GLP1 signaling normally acts to maintain or enhance sweet taste sensitivity, thus providing a peripheral mechanism for the reduction of ingestive behaviors and appetite in the context of an animal's metabolic state (Shin et al. 2008). Therefore, the increased expression of DPP4 and proglucagon in the $\mathrm{CV}$ of T2DM rats after liraglutide treatment may reflect its role in satiety, weight loss, and glucose lowering, with a mechanism that likely involves interaction among paracrine, peripheral sensors, and the central nervous system. A previous study showed that the DPP4 activity levels in the hypothalamus decreased in monosodium glutamate-induced obese and fooddeprived animals compared with the controls (Alponti et al. 2011), indicating that DPP4 may participate in the energy balance in the hypothalamus. Furthermore, GLP1R on POMC/CART-expressing ARC neurons in mice was suggested to be the primary factor mediating liraglutide-induced weight loss (Anna et al. 2014). In our study, we found that GLP1R level is evaluated in the hypothalamus of diabetic rats with liraglutide. Based on the present results, we suspect that liraglutide treatmentinduced changes in the DPP4 and GLP1R level in the hypothalamus may be involved in its beneficial effects for the control of food intake and energy balance.

In addition to functioning in the inactivation of peptides, DPP4 can also interact with adenosine deaminase on the surface of $\mathrm{T}$ cells and is thus involved in $\mathrm{T}$ cell activation. Considering the importance of immunity and inflammation for the development of T2DM and its complications such as taste impairment, DPP4 expression changes appear to be associated with the complex network of the pathogenesis of T2DM. However, the effective nature of DPP4 changes may vary, depending on the local or general conditions, paracrine or endocrine activity, and interactions between hormones, among other factors.

In summary, we have demonstrated that DPP4 is expressed in the taste buds of the $\mathrm{CV}$, which implicates its role in the gustatory systems. Furthermore, the observed changes in the expression levels of DPP4 in the CV and hypothalamus of T2DM rats after liraglutide treatment indicate that it might play a major role in the mechanism by which liraglutide helps to regulate appetite and energy homeostasis in patients. However, the present study could not provide a definitive mechanism of how liraglutide treatment improves the taste sensitivity or metabolic homeostasis of whole body, which require further investigation. Nevertheless, these findings are beneficial to enhance understanding of the effects and interactions of GLP1 and DPP4, as well as the relationship between peripheral sensors and the central nervous system on the regulation of taste sensitivity, feeding, and energy balance.

Declaration of interest

The authors declare that there is no conflict of interest that could be perceived as prejudicing the impartiality of the research reported.

\section{Funding}

This research did not receive any specific grant from any funding agency in the public, commercial, or not-for-profit sector.

Published by Bioscientifica Ltd. 


\section{Acknowledgments}

The authors are grateful to all study participants.

\section{References}

Alponti RF, Frezzatti R, Barone JM, VdeS Algre \& Sliveira PF 2011 Dipeptidyl peptidase IV in the hypothalamus and hippocampus of monosodium glutamate obese and food-deprived rats. Metabolism 60 234-242. (doi:10.1016/j.metabol.2009.12.031)

Anna S, Jacob J, Baquero AF, Hecksher-Sørensen J, Cowley MA, Dalbøge LS, Hansen G, Grove KL, Pyke C, Raun K, et al. 2014 The arcuate nucleus mediates GLP-1 receptor agonist liraglutidedependent weight loss. Journal of Clinical Investigation 124 4473-4488. (doi:10.1172/JCI75276)

Cummings BP, Stanhope KL, Graham JL, Baskin DG, Briffen SC, Nilsson C, Sams A, Knudsen LB, Raun K \& Havel PJ 2010 Chronic administration of the glucagon-like peptide- 1 analog, liraglutide, delays the onset of diabetes and lowers triglycerides in UCD-T2DM rats. Diabetes 59 2653-2661. (doi:10.2337/db09-1564)

Degn KB, Juhl CB, Sturis J, Jakobsen G, Brock B, Chandramouli V, Rungby J, Landau BR \& Schmitz O 2004 One week's treatment with the long-acting glucagon-like peptide 1 derivative liraglutide (NN2211) markedly improves 24 -h glycemia and $\alpha$ - and $\beta$-cell function and reduces endogenous glucose release in patients with type 2 diabetes. Diabetes 53 1187-1194. (doi:10.2337/ diabetes.53.5.1187)

Dinjens WN, ten-Kate J, van-der-Linden EP, Wijnen JT, Khan PM \& Bosman FT 1989 Distribution of adenosinedeaminase complexing protein (ADCP) in human tissues. Journal of Histochemistry \& Cytochemistry 37 1869-1875. (doi:10.1177/37.12.2573631)

Dubový P 1988 A study of the dipeptidylpeptidase IV activity in cat fungiform papillae: light and electron microscope histochemistry. Acta Histochemica 83 173-184. (doi:10.1016/S00651281(88)80054-0)

Feng XH, Liu XM, Zhou LH, Wang J \& Liu GD 2008 Expression of glucagon-like peptide-1 in the taste buds of rat circumvallate papillae. Acta Histochemica 110 151-154. (doi:10.1016/ j.acthis.2007.10.005)

Feng XH, Zhou LH, Wang D \& Yuan X 2012 GLP-1 expression in von Ebner's gland of diabetic rats. Peptides 38 137-141. (doi:10.1016/ j.peptides.2012.09.002)

Hildebrandt M, Reutter W, Arck P, Rose M \& Klapp BF 2000 A guardian angel: theinvolvement of dipeptidyl peptidase IV in psychoneuroendocrine function, nutrition and immune defence. Clinical Science 99 93-104. (doi:10.1042/cs0990093)

Hildebrandt M, Rose M, Mönnikes H, Reutter W, Keller W \& Klapp BF 2001 Eatingdisorders: a role for dipeptidyl peptidase IV in nutritional control. Nutrition 17 451-454. (doi:10.1016/S0899. 9007(01)00547-0)

Hopsu-Havu VK \& Glenner GG 1966 A new dipeptide naphthylamidase hydrolyzing glycyl-prolyl-beta-naphthylamide. Histochemie $\mathbf{7}$ 197-201. (doi:10.1007/BF00577838)

Itou M, Kawaguchi T, Taniguchi E \& Sata M 2013 Dipeptidyl peptidase-4: a key player in chronic liver disease. World Journal of Gastroenterology 19 2298-2306. (doi:10.3748/ wjg.v19.i15.2298)

Kameoka J, Tanaka T, Nojima Y \& Schlossman SF \& Morimoto C 1993 Direct association of adenosine deaminase with a $\mathrm{T}$ cell activation antigen, CD26. Science 261 466-469. (doi:10.1126/science.8101391)

Kikuchi M, Fukuyama K \& Epstein WL 1988 Soluble dipeptidyl peptidase IV from terminal differentiated rat epidermal cells: purification and its activity on synthetic and natural peptides. Archives of Biochemistry and Biophysics 266 369-376. (doi:10.1016/0003-9861(88)90268-8)
Kirino Y, Sei M, Kawazoe K, Minakuchi K \& Sato Y 2012 Plasma dipeptidyl pepti-dase 4 activity correlates with body mass index and the plasma adiponectinconcentration in healthy young people. Endocrine Journal 59 949-953. (doi:10.1507/endocrj.EJ12-0158)

Lee SA, Kim YR, Yang EJ, Kwon EJ, Kim SH, Kanq SH, Park DB, Oh BC, Kim J, Heo ST, et al. 2013 CD26/DPP4 levels in peripheral blood and $\mathrm{T}$ cells in patients with type 2 diabetes mellitus. Journal of Clinical Endocrinology \& Metabolism 98 2553-2561. (doi:10.1210/jc.20124288)

Liehua L, Bilal O, Piero M \& Bo A 2014 Dipeptidyl peptidase-4 (DPP-4): localization and activity in human and rodent islets. Biochemical \& Biophysical Research Communications 453 398-404. (doi:10.1016/j. bbrc.2014.09.096)

Mao Z, Yang J, Dong Z \& Hui XU 2009 Over expression of dipeptidyl peptidase IV/CD26 on gingiva of type 2 diabetic rats. Chinese Journal of Conservative Dentistry 19 431-430. (doi:10.15956/j.cnki. chin.j.conserv.dent.2009.08.003)

Martin B, Dotson CD, Shin YK, Ji S, Drucker DJ, Maudsley S \& Munger SD 2009 Modulation of taste sensitivity by GLP-1 signaling in taste buds. Annals of the New York Academy of Sciences $\mathbf{1 1 7 0}$ 98-101. (doi:10.1111/j.1749-6632.2009.03920.x)

Martin C, Passilly-Degrace P, Chevrot M, Ancel D, Sparks SM, Drucker DJ \& Besnard P 2012 Lipid-mediated release of GLP-1 by mouse taste buds from circumvallate papillae: putative involvement of GPR120 and impact on taste sensitivity. Journal of Lipid Research $\mathbf{5 3}$ 2256-2265. (doi:10.1194/jlr.M025874)

Mentlein R 1999 Dipeptidyl-peptidase IV (CD26) -role in the inactivation of regulatory peptides. Regulatory Peptides 85 9-24. (doi:10.1016/S0167-0115(99)00089-0)

Mentzel S, Dijkman HB, Van Son JP, Koene RA \& Assmann KJ 1996 Organ distribution of aminopeptidase A and dipeptidyl peptidase IV in normal mice. Journal of Histochemistry \& Cytochemistry $\mathbf{4 4}$ 445-461. (doi:10.1177/44.5.8627002)

Niswender K, Pi-Sunyer X, Buse J, Jensen KH, Toft AD, Russell-Jones D \& Zinman B 2013 Weight change with liraglutide and comparator therapies: an analysis of seven phase 3 trials from the liraglutide diabetes development programme. Diabetes Obesity \& Metabolism 15 42-54. (doi:10.1111/j.1463-1326.2012.01673.x)

Peterson GE \& Pollom RD 2010 Liraglutide in clinical practice: dosing, safety and efficacy. International Journal of Clinical Practice Supplement 64 35-43. (doi:10.1111/j.1742-1241.2010.02498.x)

Raun K, von Voss P, Gotfredsen CF, Golozoubova V, Rolin B \& Knudsen LB 2007 Liraglutide, a long-acting glucagon-like peptide-1 analog, reduces body weight and food intake in obese candy-fed rats, whereas a dipeptidyl peptidase-IV inhibitor, vildagliptin, does not. Diabetes 56 8-15. (doi:10.2337/db06-0565)

Reagan-Shaw S, Nihal M \& Ahmad N 2008 Dose translation from animal to human studies revisited. FASEB Journal 22 659-661. (doi:10.1096/ fj.07-9574LSF)

Röhrborn D, Wronkowitz N \& Eckel J 2015 DPP4 in Diabetes. Frontiers in Immunology 6 386. (doi:10.3389/fimmu.2015.00386)

Shen T, Kaya N, Zhao FL, Lu SG, Cao Y \& Hemess S 2005 Co-expression patterns of the neuropeptides vasoactive intestinal peptide and cholecystokin in with the transduction molecules a-gustducin and T1R2 in rat taste receptor cells. Neuroscience 130 229-238. (doi:10.1016/j.neuroscience.2004.09.017)

Shi SR, Cote RJ, Liu C, Yu MC, Castelao JE, Ross RK \& Taylor CR 2002 A modified reduced-temperature antigen retrieval protocol effective for use with a polyclonal antibody to cyclooxygenase-2 (PG 27). Applied Immunohistochemistry \& Molecular Morphology 10 368-373.

Shin YK, Martin B, Golden E, Dotson CD, Maudsley S, Kim W, Jang HJ, Mattson MP, Drucker DJ \& Egan JM 2008 Modulation of taste sensitivity by GLP-1 signaling. Journal of Neurochemistry $\mathbf{1 0 6}$ 455-463. (doi:10.1111/j.1471-4159.2008.05397.x)

Srinivasan K, Viswanad B, Asrat L, Kaul CL \& Ramarao P 2005 Combination of high-fat diet-fed and low-dose streptozotocin-treated

Published by Bioscientifica Ltd 
rat: a model for type 2 diabetes and pharmacological screening. Pharmacological Research 52 313-320. (doi:10.1016/j.phrs.2005.05.004)

Stengel A, Goebel-Stengel M, Teuffel P, Hofmann T, Buße P, Kobelt P, Rose M \& Klapp BF 2014 Obese patients have higher circulating protein levels of dipeptidyl peptidase IV. Peptides $\mathbf{6 1} 75-82$. (doi:10.1016/j.peptides.2014.09.006)
Zhang XJ, Wang YQ, Long Y, Wang L, Li Y, Gao FB \& Tian HM 2013 Alteration of sweet taste in high-fat diet induced obese rats after 4weeks treatment with exenatide. Peptides 47 115-123. (doi:10.1016/j.peptides.2013.07.015)

Ziółkowska J 2006 Oral health status and dental service needs of diabetic patients. Annales Academiae Medicae Stetinensis 52 103-114.

Received in final form 26 April 2016

Accepted 4 May 2016

Accepted Preprint published online 5 May 2016
Published by Bioscientifica Ltd. 